\title{
Comparison of the efficacy of the tumour necrosis factor $\alpha$ blocking agents adalimumab, etanercept, and infliximab when added to methotrexate in patients with active rheumatoid arthritis
}

\author{
M C Hochberg, J K Tracy, M Hawkins-Holt, R H Flores
}

Ann Rheum Dis 2003;62(Suppl II):ii 13-ii 16

Objective: To determine, using the method of adjusted indirect comparisons, whether there are differences in efficacy of tumour necrosis factor (TNF $\alpha$ ) blocking agents, as measured by the rate ratios for American College of Rheumatology (ACR) 20, 50, and 70 responses, in patients with rheumatoid arthritis with an incomplete response to methotrexate.

Methods: A systematic review was performed to identify placebo controlled trials of 24-30 weeks' duration of combination therapy that used a step-up approach with the addition of TNF $\alpha$ blocking agents to methotrexate. The method of "adjusted indirect comparisons" was used to compare results across trials to determine the relative risk for an ACR20 or 50 response.

Results: Placebo controlled trials for adalimumab, etanercept, and infliximab provided data on ACR2O and 50 responses. Both the similarity of demographic and disease characteristics of patients at entry, and the homogeneity of response rates in the placebo groups across trials, suggested that comparing results across trials was valid. The relative risk for obtaining an ACR20 and 50 response derived from the adjusted indirect comparisons of the TNF $\alpha$ blocking agents did not significantly differ from unity.

Conclusion: The analysis showed that the three currently marketed TNF $\alpha$ blocking agents have similarly efficacy when added to methotrexate in the treatment of patients with rheumatoid arthritis with active disease.

$\mathrm{R}$ heumatoid arthritis (RA) is a common disease affecting about $1 \%$ of adults aged 35 and above and over $2 \%$ of adults aged 60 and above in the United States. ${ }^{12}$ Treatment of patients with RA involves a multidisciplinary approach with patient education, physical and occupational therapy, non-steroidal anti-inflammatory drugs (NSAIDs), and disease modifying antirheumatic drugs (DMARDs). ${ }^{3}$ Methotrexate is presently the preferred DMARD for patients with active RA because of its documented short term efficacy in placebo controlled clinical trials and long term effectiveness in clinical practice. ${ }^{4-7}$ Despite this, many patients fail to enter remission and continue to have signs and symptoms of active disease while taking a maximally tolerated dose. Therapeutic options in such situations include switching patients from oral to parenteral methotrexate, ${ }^{8}$ stopping methotrexate and starting another DMARD, or continuing methotrexate and adding another agent (for example, another DMARD or a tumour necrosis factor $\alpha$ (TNF $\alpha$ ) blocking agent). This last approach is one form of combination therapy referred to as the "step-up" strategy. 'We previously reported a systematic review of randomised placebo controlled trials of the "step-up" strategy in patients with active RA who were receiving maximally tolerated doses of methotrexate and found that the proportion of patients with American College of Rheumatology (ACR) 20 responses did not significantly differ between patients receiving cyclosporin, etanercept, infliximab, or leflunomide. ${ }^{10}$ Since that analysis was performed, data from the clinical development programme of adalimumab, a human derived recombinant monoclonal antibody to TNF $\alpha$, were submitted to the US Food and Drug Administration, ${ }^{11}{ }^{12}$ and adalimumab was approved for use in the United States as well as within the European Union. Herein, we report the results of analyses that indirectly compare the efficacy of the three approved TNF $\alpha$ blocking agents, adalimumab, etanercept, and infliximab, when added to methotrexate in patients with RA with an incomplete response to methotrexate.

\section{METHODS}

\section{Literature review}

The methods of the literature review were published previously. ${ }^{10}$ For the purposes of this paper we updated the review to include articles identified in a new Medline search up to the end of December 2002 and abstracts from the 2001 and 2002 annual meetings of the American College of Rheumatology and European League Against Rheumatism. In addition, we reviewed the Humira (adalimumab) briefing package submitted to the Food and Drug Administration Arthritis Advisory Committee on 4 February 2003 (http:// www.fda.gov/ohrms/dockets/ac/03/briefing/3930B1_02_AAbbott-Humira.pdf).

\section{Data extraction}

Placebo controlled, double blind, randomised clinical trials of at least 24 weeks' duration were selected for inclusion in this analysis. Data extracted included baseline patient characteristics (age, sex, race, duration of RA, proportion rheumatoid factor positive), concomitant treatment (use of NSAIDs and glucocorticoids), study treatment (study drug and regimen, methotrexate dose and duration), eligibility criteria (definition of active disease), baseline values for the WHO/ILAR core set variables (number of painful/tender joints, number of swollen joints, pain scores, patient and global assessment of disease activity, acute phase reactants and physical disability scores), ${ }^{13}$ and outcome measures (ACR20, 50, and 70) at either

Abbreviations: ACR, American College of Rheumatology; $\mathrm{Cl}$, confidence interval; DMARD, disease modifying antirheumatic drug; NSAID, non-steroidal anti-inflammatory drug; RA, rheumatoid arthritis; $\mathrm{RR}$, rate ratio; TNF $\alpha$, tumour necrosis factor $\alpha$ 
Table 1 Characteristics of patients enrolled in placebo controlled, double blind, randomised controlled trials of the addition of tumour necrosis factor $\alpha$ blocking agents to methotrexate in patients with active rheumatoid arthritis

\begin{tabular}{|c|c|c|c|c|c|c|c|}
\hline \multirow[b]{2}{*}{ First author } & \multirow[b]{2}{*}{$\begin{array}{l}\text { Therapeutic } \\
\text { agent }\end{array}$} & \multicolumn{2}{|c|}{ No of patients } & \multirow[b]{2}{*}{$\begin{array}{l}\text { Age } \\
\text { (years) }\end{array}$} & \multirow[b]{2}{*}{$\begin{array}{l}\text { Female } \\
(\%)\end{array}$} & \multirow[b]{2}{*}{$\begin{array}{l}\text { Duration of } \\
\text { RA (years) }\end{array}$} & \multirow[b]{2}{*}{$\begin{array}{l}\mathrm{RF}(+) \\
(\%)\end{array}$} \\
\hline & & Placebo & $\begin{array}{l}\text { Active } \\
\text { treatment }\end{array}$ & & & & \\
\hline Weinblatt ${ }^{21}$ & Etanercept & 30 & 59 & 50 & 84 & 13 & 86 \\
\hline Maini ${ }^{19}$ & Infliximab & 88 & 340 * & 53 & 78 & 8.5 & 81 \\
\hline Weinblatt ${ }^{22}$ & Adalimumab & 62 & $67 \dagger$ & 56 & 78 & 12 & NS \\
\hline Keystone ${ }^{23}$ & Adalimumab & 200 & $207 t$ & 56 & 75 & 11 & 79 \\
\hline
\end{tabular}

NS, not stated; RF, rheumatoid factor.

*Combined treatment groups $(3 \mathrm{mg} / \mathrm{kg}$ every 4 weeks, $3 \mathrm{mg} / \mathrm{kg}$ every 8 weeks, $10 \mathrm{mg} / \mathrm{kg}$ every 4 weeks $10 \mathrm{mg} / \mathrm{kg}$ every 8 weeks).

†Treatment group that received $40 \mathrm{mg}$ every other week.

the end of trial or 24-30 weeks' duration if the trial lasted for 52 weeks. ${ }^{14} 15$

\section{Data analysis}

The rate ratio (RR) and its $95 \%$ confidence interval (CI) for patients achieving an ACR20 and 50 response for the active treatment group compared with placebo was calculated for each of the three TNF $\alpha$ blocking agents. When there was more than one informative placebo controlled trial for a given agent, data were combined across the trials using the MantelCochrane-Haenszel technique to give a more stable estimate of the RR. ${ }^{16}$ The proportion of patients randomly allocated to receive placebo who achieved an ACR20, 50, or 70 response was compared across treatments using a $\chi^{2}$ test; for this calculation, Yates's correction was used when the number of placebo treated patients achieving an outcome was five or fewer in any of the trials. The comparison of the three TNF blocking agents with each other was performed using the method of adjusted indirect comparisons as described by Bucher and colleagues ${ }^{17}$ and Song and colleagues. ${ }^{18}$ All analyses were performed using EpiCalc 2000, version 1.02 (Gilman J and Myatt M, Brixton Books, 1998).

\section{RESULTS}

\section{Literature review}

We identified four double blind, placebo controlled, randomised clinical trials that examined the addition of TNF blocking agents to methotrexate in a "step-up" strategy in patients with active RA. ${ }^{19-23}$ Two articles reported results from the same trial adding infliximab to methotrexate ${ }^{1920}$; only data from the article reporting results after 30 weeks of treatment was included in this analysis. Data from the phase III randomised placebo controlled trial of adalimumab in patients with active RA despite receiving methotrexate treatment were presented at the ACR meeting in 2002 ${ }^{23}$; the data in the Humira briefing document for ACR response rates at 24 weeks were abstracted for the purpose of this review.

Table 1 shows the demographic and disease characteristics of the patients enrolled in the five studies. On average, patients were middle-aged with a mean or median age in the sixth decade, and predominantly white women who were rheumatoid factor positive and had disease duration of about 10 years. All were receiving stable doses of methotrexate; mean or median weekly doses ranged from 16 to $19 \mathrm{mg}$ a week.

\section{Study descriptions}

Maini and colleagues added infliximab at four different dosage regimens, or placebo by intravenous infusion, to 428 patients with RA who had been receiving oral or parenteral methotrexate for at least three months and a stable dose of at least $12.5 \mathrm{mg} /$ week for at least four weeks. All patients had active disease defined as six or more swollen and tender joints together with two of the following: morning stiffness of at least 45 minutes, erythrocyte sedimentation rate greater than $28 \mathrm{~mm} / \mathrm{lst} \mathrm{h}$, and C reactive protein greater than $20 \mathrm{mg} / \mathrm{l} .{ }^{19}$ The median weekly dose of methotrexate was $15 \mathrm{mg}$ and $72 \%$ of patients were receiving at least $15 \mathrm{mg} /$ week; there was no significant difference in methotrexate dose or duration of treatment across treatment groups. As there were no significant differences either in baseline variables or in the proportion of patients with an ACR20 response after 30 weeks of treatment between the four infliximab treatment groups, data from these four groups were pooled for the purposes of the present analysis. Thirty five of 88 patients treated with placebo treated and 47 of 293 treated with infliximab failed to complete 30 weeks of treatment.

Weinblatt and colleagues added etanercept at a dose of 25 $\mathrm{mg}$, or placebo injected subcutaneously twice weekly, to 89 patients with RA who had been receiving methotrexate for at least six months and a stable dose of $15-25 \mathrm{mg} /$ week for the last four weeks, and had active disease manifest by at least six joints that were swollen and six that were tender at the time of enrolment. ${ }^{21}$ The mean weekly dose of methotrexate at entry was $18 \mathrm{mg}$ in the placebo group and $19 \mathrm{mg}$ in the etanercept group. Six of 30 patients treated with placebo and only 2 of 59 treated with etanercept failed to complete 24 weeks of treatment.

Weinblatt and colleagues added adalimumab at a dose of 20, 40 , or $80 \mathrm{mg}$ every other week or placebo by subcutaneous injection to 271 patients with RA who had been receiving methotrexate at their maximal tolerated dose of between 12.5 and $25 \mathrm{mg} /$ week for at least six months and a stable dose for at least four weeks, and had active disease defined by the presence of nine or more tender joints and six or more swollen joints. ${ }^{22}$ The mean weekly dose of methotrexate at entry was $16.5 \mathrm{mg}$ in the placebo group and $16.4 \mathrm{mg}$ in the group receiving adalimumab $40 \mathrm{mg}$ every other week. Only data from patients randomly allocated to receive placebo or adalimumab $40 \mathrm{mg}$ every other week were abstracted for the purpose of this analysis

Keystone and colleagues added adalimumab at a dose of 20 mg weekly or $40 \mathrm{mg}$ every other week or placebo by subcutaneous injection to 619 patients with RA who had been receiving methotrexate at their maximal tolerated dose for at least three months and a stable dose for at least four weeks, and had active disease defined by the presence of nine or more tender joints, six or more swollen joints, and a $\mathrm{C}$ reactive protein level of $10 \mathrm{mg} / \mathrm{l}$ or greater. ${ }^{23}$ The mean weekly dose of methotrexate at entry was $16.7 \mathrm{mg}$ in both the placebo group and the group receiving adalimumab $40 \mathrm{mg}$ every other week. Only data from patients randomly allocated to receive placebo or adalimumab $40 \mathrm{mg}$ every other week were abstracted for the purpose of this analysis.

\section{ACR20, 50 and 70 responses in the placebo groups}

The proportion of patients with an incomplete response to methotrexate who were randomly allocated to receive placebo 
Table 2 Adjusted indirect comparisons of the efficacy of TNF $\alpha$ blocking agents in placebo controlled, randomised, double blind trials in patients with active rheumatoid arthritis with an incomplete response to methotrexate

\begin{tabular}{lll}
\hline \multirow{2}{*}{ Comparison } & \multicolumn{2}{l}{ Relative risk (95\% CI) } \\
\cline { 2 - 3 } & ACR 20 & ACR 50 \\
\hline Etanercept $v$ adalimumab & 1.10 & 2.60 \\
Infliximab $v$ adalimumab & $(0.57$ to 2.12$)$ & $(0.35$ to 19.0$)$ \\
Etanercept $v$ infliximab & $(0.66$ to 1.73$)$ & 1.35 \\
& 1.03 & 1.47 to 3.85$)$ \\
& $(0.49$ to 2.18$)$ & $(0.22$ to 17.0$)$ \\
\hline
\end{tabular}

$\mathrm{ACR}$, American College of Rheumatology; $\mathrm{Cl}$, confidence intervals.

and completed 24-30 weeks of treatment and obtained an ACR20, 50, and 70 response varied from 20 to $30 \%, 3$ to $10 \%$, and 0 to $3 \%$, respectively; none of the differences across the studies reached statistical significance (data not shown).

\section{Adjusted indirect comparisons of TNF $\alpha$ blocking agents} Table 2 shows the RRs and 95\% CIs for the adjusted indirect comparisons of the TNF $\alpha$ blocking agents. The RRs for achieving an ACR20 response all clustered about unity, suggesting no difference in efficacy between the TNF $\alpha$ blocking agents for this outcome. The RRs for achieving an ACR50 response suggested that etanercept might be more efficacious than both adalimumab and infliximab; however, the 95\% CIs of each were wide and included unity. As none of the patients randomly allocated to receive placebo in the trials of etanercept or infliximab achieved an ACR70 response, we were unable to calculate RRs for these agents and perform adjusted indirect comparisons with adalimumab for this outcome.

\section{DISCUSSION}

TNF $\alpha$ blocking agents are currently indicated for the treatment of patients with active RA after an adequate trial of a DMARD, most commonly methotrexate. ${ }^{24}$ The results of the present analysis suggest that in patients with an incomplete response to methotrexate the addition of either adalimumab, etanercept, or infliximab is associated with a comparable response as defined by the ACR20 or 50 responder index after 24-30 weeks of combination therapy. These findings update and extend the results of our earlier analysis that was limited to etanercept and infliximab and used different methodology. ${ }^{10}$

Although the TNF $\alpha$ blocking agents differ in chemical structure and specific mechanism of action, they are generally recognised to comprise a new class of biological agents based on their similar pharmacological effects. The practising rheumatologist is thus faced with a situation where he/she has to choose between three products that have all been shown to improve the signs and symptoms and inhibit the progression of structural joint damage in patients with active RA. McAlister and colleagues suggested an approach to this dilemma based on a hierarchy of evidence. ${ }^{25}$ They defined four levels of evidence, the highest being provided by "head-tohead" randomised clinical trials that directly compared clinically important outcomes for two or more drugs of interest. The major limitation to the conduct of such trials is the large sample size required to demonstrate either differences between, or equivalence of, the treatments on a clinically important outcome. In the absence of such direct "head-tohead" comparisons, they noted that the second highest level of evidence was provided by indirect comparisons of the treatments using the method outlined by Bucher and colleagues. ${ }^{17}$
Bucher and colleagues developed a model for making adjusted indirect comparisons of the magnitude of treatment effects that produces an unbiased estimate of the relative efficacy of the treatments. This method preserves the randomisation of the original treatment groups and allows the comparison of the magnitude of the treatment effect in comparison with a placebo group in the randomised trials; it is thus better than a simple indirect comparison of treatment effects across trials that do not consider the placebo response within each trial. The authors did note that there were several assumptions that should be fulfilled in order to support the inferences drawn from these comparisons, including similarity of methodology in trial design and measurement of clinically important outcomes, and consistency of treatment effect in different subgroups of patients. Inherent limitations to the inferences drawn from adjusted indirect comparisons, particularly because of wider confidence intervals due to greater variance from lower efficiency, occur even in the absence of any systematic bias.

Song and colleagues recently examined the validity of adjusted indirect comparisons by using data from published meta-analyses of randomised controlled trials. ${ }^{18}$ They identified 28 systematic reviews that provided data allowing a total of 44 comparisons between direct and adjusted indirect comparisons of competing interventions. Significant discrepancies were noted in only three of the 44 comparisons; only one of these was felt to be of clinical importance and was explained by differences in dosage of the treatments used in the studies for the indirect comparison. The direct comparisons were more likely to show significant differences between treatments than the adjusted indirect comparisons; indeed, of 19 direct comparisons that showed significant differences between treatments, 10 adjusted indirect comparisons were no longer significant. This is consistent with the lower precision in the adjusted indirect comparison. These authors felt that adjusted indirect comparisons were useful when there was no direct evidence to compare competing interventions.

We examined the assumptions required to allow the comparison of outcomes of different placebo controlled, double blind, randomised clinical trials. ${ }^{17}$ Firstly, one assumes that the samples of patients in the different trials are drawn from the same population of patients. The validity of this assumption can be assessed in part by examining the demographic and baseline clinical variables of the patients enrolled in the trials (table 1). The median age of patients was similar and ranged from 50 to 55 years. The majority of patients enrolled in these trials were white women. The mean or median duration of disease was also similar and ranged from 8 to 13 years. Although there were subtle differences in the definition of active disease across trials, the mean or median number of painful/tender joints and swollen joints was also similar across trials, ranging from 28 to 30 and 17 to 20 , respectively. Mean or median doses of methotrexate were similar across the trials. Other parameters of disease activity included in the WHO/ILAR core set were also similar across trials (see also Fleischmann ${ }^{26}$; Dayer and Matteson ${ }^{27}$ ). Thus, it appears that the patients enrolled in these trials had comparable demographic and clinical features at baseline.

Another method of assessing the validity of this assumption is to compare the proportion of patients randomly allocated to receive placebo who develop the study outcome. Indeed, the proportion of patients randomly allocated to receive placebo who completed the 24-30 weeks of the trials and developed an ACR20, 50, and 70 response was statistically comparable with an overall proportion of 25,8 , and $2 \%$, respectively. Thus, it appears that the patients enrolled in these different trials were similar to one another, allowing reasonable inferences from the comparison of these data to the extent that can be drawn from the published reports.

The conclusions of this analysis may be limited by the use of the ACR20 and 50 responder index as the study outcomes. The 
ACR20 responder index was originally developed to differentiate active DMARDs from placebo. ${ }^{14}$ All the agents tested in patients with an inadequate response to methotrexate in the placebo controlled trials and included in the present analysis were significantly better than placebo in patients with an inadequate response to methotrexate. The ACR20 response, however, may not be sensitive enough to differentiate between two or more active agents. Indeed, when examining the ACR50 response, there was a suggestion that etanercept might be more efficacious than the other TNF $\alpha$ blocking agents, although the rate ratios were not statistically significant because of wide confidence intervals, attributable to the small numbers of subjects enrolled in the etanercept trial. If direct comparisons are to be performed between TNF $\alpha$ blocking agents, the ACR50 or 70 responder index should be considered as the primary outcome rather than the ACR20.

Decisions about the choice of treatment include not only efficacy but also safety and tolerability, route of administration, and costs and availability of insurance coverage for reimbursement of treatment expenses. With regard to safety and tolerability, it appears that patients randomly allocated to receive either adalimumab or etanercept did not have a significantly greater proportion of withdrawals than patients randomly allocated to receive placebo in the trials examined in this analysis. Recent attention, however, has been focused on rare adverse events with TNF $\alpha$ blocking agents, particularly serious infections, mycobacterial and other opportunistic infections, malignancy including lymphoma, congestive heart failure, and demyelinating disease with etanercept. ${ }^{28}{ }^{29}$ Readers should closely review product inserts for complete data on adverse effects of these agents when used either individually or in combination with methotrexate.

Finally, the results of this analysis provide strong evidence for several alternatives for the patient with RA who has had an inadequate response to methotrexate therapy. Long term observational studies using patient registries are needed to examine the long term effectiveness and safety of these combinations.

\section{Authors' affiliations}

M C Hochberg, J K Tracy, M Hawkins-Holt, R H Flores, Division of Rheumatology and Clinical Immunology, Department of Medicine, and Department of Epidemiology and Preventive Medicine, University of Maryland School of Medicine, Baltimore, MD 21201 USA

Correspondence to: Dr M C Hochberg, 10 S Pine St, MSTF 8-34, Baltimore, MD 21201 USA; mhochber@umaryland.edu

\section{REFERENCES}

1 Gabriel SE. The epidemiology of rheumatoid arthritis. Rheum Dis Clin North Am 2001:27:269-81.

2 Rasch EK, Hirsch R, Faulose-Ram R, Hochberg MC. Prevalence of rheumatoid arthritis in persons 60 years of age and older in the United States: effect of different methods of case classification. Arthritis Rheum 2003;48:917-26.

3 ACR. American College of Rheumatology Subcommittee on Rheumatoid Arthritis Guidelines. Guidelines for the management of rheumatoid arthritis: 2002 update. Arthritis Rheum 2002;46:328-46.

4 Weinblatt ME, Coblyn JS, Fox DA, Fraser PA, Holdsworth DE, Glass $\mathrm{DN}$, et al. Efficacy of low-dose methotrexate in rheumatoid arthritis. $\mathrm{N}$ Engl J Med 1985;312:818-22.

5 Williams HJ, Wilkens RF, Samuelson CO Jr, Alarcon GS, Guttadauria $M$, Yarboro C, et al. Efficacy of low-dose oral pulse methotrexate and placebo in the treatment of rheumatoid arthritis: a controlled clinical trial. Arthritis Rheum 1985;28:721-30.
6 Kremer JM. Safety, efficacy, and mortality in a long-term cohort of patients with rheumatoid arthritis taking methotrexate: followup after a mean of 13.3 years. Arthritis Rheum 1997;40:984-5.

7 Weinblatt ME, Maier AL, Fraser PA, Coblyn JS. Long-term prospective study of methotrexate in rheumatoid arthritis: conclusion after 132 months of therapy. J Rheumatol 1998;25:238-42.

8 Osman A, Mulherin D. Is parenteral methotrexate worth trying? Ann Rheum Dis 2001;60:432.

9 Verhoeven AC, Boers M, Tugwell P. Combination therapy in rheumatoid arthritis: updated systematic review. Br J Rheumatol 1998;37:612-19.

10 Hochberg MC, Tracy JK, Flores RH. "Stepping-up" from methotrexate: a systematic review of randomized placebo-controlled trials in patients with active rheumatoid arthritis with an incomplete response to methotrexate. Ann Rheum Dis 2001;60(suppl III):iii51-4

11 Rau R. Adalimumab (a fully human anti-tumor necrosis factor $\alpha$ monoclonal antibody) in the treatment of active rheumatoid arthritis: the initial results of five trials. Ann Rheum Dis 2002;61 (uppl II):ii70-3.

12 Abbott Laboratories. Humira ${ }^{\mathrm{TM}}$ (adalimumab). Product information. North Chicago, IL, USA: Abbott Laboratories, December 2002.

13 Boers M, Tugwell P, Felson DT, van Riel P, Kirwan J, Edmonds J, et al. World Health Organization and International League for Associations of Rheumatology core endpoints for symptom modifying antirheumatoid drugs in rheumatoid arthritis clinical trials. J Rheumatol 1994;21/suppl 41):86-9.

14 Felson DT, Anderson JJ, Boers M, Bombardier C, Chernoff M, Fried B, et al. The American College of Rheumatology preliminary core set of disease activity measures for rheumatoid arthritis clinical trials. Arthritis Rheum 1993:36:729-40.

15 Felson DT, Anderson JJ, Lange MLM, Wells G, LaValley MP. Should improvement in rheumatoid arthritis clinical trials be defined as fifty percent or seventy percent improvement in core set measures rather than twenty percent? Arthritis Rheum 1998;41:1564-70.

16 Pagano M, Gauvreau K. Principles of biostatistics. Belmont, CA: Duxbury Press, 1993:341-52.

17 Bucher HC, Guyatt GH, Griffith LE, Walter SD. The results of direct and indirect treatment comparisons in meta-analysis of randomized controlled trials. J Clin Epidemiol 1997;50:683-91.

18 Song F, Altman DG, Glenny A-M, Deeks JJ. Validity of indirect comparison for estimating efficacy of competing interventions: empirical evidence from published meta-analyses. BM 2003;326:472-6.

19 Maini R, St Clair EW, Breedveld F, Furst D, Kalden J, Weisman M, et al Infliximab (chimeric anti-tumour necrosis factor $\alpha$ monoclonal antibody) versus placebo in rheumatoid arthritis patients receiving concomitant methotrexate: a randomised phase III trial. Lancet 1999:354:1932-9.

20 Lipsky PE, van der Heijde DMFM, St Clair EW, Furst DE, Breedveld FC, Kalden JR, et al. Infliximab and methotrexate in the treatment of rheumatoid arthritis. N Engl J Med 2000;343:1594-602

21 Weinblatt ME, Kremer JM, Bankhurst AD, Bulpitt KJ, Fleischmann RM, Fox $\mathrm{RI}$, et al. A trial of etanercept, a recombinant tumor necrosis factor receptor: Fc fusion protein, in patients with rheumatoid arthritis receiving methotrexate. N Engl J Med 1999;340:253-9.

22 Weinblatt ME, Keystone EC, Furst DE, Moreland LW, Weisman MH, Birbara CA, et al. Adalimumab, a fully humanized anti-tumor necrosis factor $\alpha$ monoclonal antibody, for the treatment of rheumatoid arthritis in patients taking concomitant methotrexate. Arthritis Rheum 2003;48:35-45

23 Keystone E, Kavanaugh AF, Sharp J, Hua Y, Teoh L, Firschkoff S, et al. Adalimumab (D2E7), a fully human anti-TNF-a monoclonal antibody, inhibits the progression of structural joint damage in patients with active RA despite concomitant methotrexate therapy [abstract]. Arthritis Rheum 2002;46(suppl):S205 (abstract 468).

24 Furst DE, Breedveld FC, Kalden JR, Smolen JS, Antoni CE, Biljsma JWJ, et al. Updated consensus statement on biological agents for the treatmen of rheumatoid arthritis and other rheumatic diseases (May 2002). Ann Rheum Dis 2002;61 (suppl II):ii2-7.

25 McAlister FA, Laupacis A, Wells GA, Sackett DL, for the Evidence-Based Medicine Working Group. Users' guide to the medical literature XIX. Applying clinical trial results. B. guidelines for determining whether a drug is exerting (more than) a class effect. JAMA 1999;282:1371-7.

26 Fleischmann RM. Examining the efficacy of biologic therapy: are there real differences? J Rheumatol 2002;29(suppl 65):27-32.

27 Dayer J-M, Bresnihan B. Targeting interleukin-1 in the treatment of rheumatoid arthritis. Arthritis Rheum 2002;46:574-8

28 Cush JJ, Matteson E. FDA Advisory Committee reviews safety of TNF inhibitors. American College of Rheumatology Hotline, September 2001 (available at http://www.rheumatology.org/research/hotline/ 0901 tnf.html).

29 Cush JJ, Kavanaugh A. FDA Meeting March 2003: update on the safety of new drugs for rheumatoid arthritis. American College of Rheumatology Hotline, March 2003 (available at http://www.rheumatology.org/ research/hotline/0303TNFL.htm) 